\title{
Transactions
}

Cite this: Dalton Trans., 2011, 40, 4217

wWw.rsc.org/dalton

PAPER

\section{The first porous MOF with photoswitchable linker molecules $\dagger+$}

\author{
Antje Modrow, ${ }^{a}$ Dordaneh Zargarani, ${ }^{b}$ Rainer Herges ${ }^{b}$ and Norbert Stock ${ }^{* a}$ \\ Received 24th November 2010, Accepted 31st January 2011 \\ DOI: 10.1039/c0dt01629b

\begin{abstract}
We synthesized a porous twofold interpenetrated $\mathrm{MOF}\left[\mathrm{Zn}_{2}(\mathrm{NDC})_{2}(\mathbf{1})\right]$ (coined CAU-5) using 3-azo-phenyl-4,4'-bipyridine (1), 2,6-naphthalenedicarboxylic acid, and $\mathrm{Zn}\left(\mathrm{NO}_{3}\right)_{2} \cdot 6 \mathrm{H}_{2} \mathrm{O}$. The azo-functionality protrudes into the pores, and can be switched, by irradiation with UV light $(365 \mathrm{~nm})$, from the thermodynamically stable trans-isomer to the $c i s$-isomer. Back-switching was achieved thermally and with an irradiation wavelength of $\lambda_{\max }=440 \mathrm{~nm}$.
\end{abstract}

\section{Introduction}

Porous materials are excellent candidates for many applications, for example in catalysis, drug delivery, gas storage or gas separation. ${ }^{1,2,3,4}$ Crystalline compounds exhibiting defined pores and cages in the microporous and mesoporous range are especially promising. While in the past microporous zeolites were the focus of interest, MOFs have been studied over the last decade because of their structural diversity. ${ }^{5,6,7,8,9}$ The structural and chemical variability is generated by a modular assembly of the MOFs that provides the possibility to adjust pore sizes and to fine-tune the shape and functionality of the pores. ${ }^{10,11}$ In general MOFs are built of inorganic bricks connected by organic linkers, which are often dicarboxylic acids and diamines. ${ }^{12}$

The first studies on MOFs focused on the synthesis of new crystalline materials exhibiting permanent porosity. Materials with large pores and cages extending to the mesoporous range were of special interest. ${ }^{6,78}$ In these studies compounds such as MIL-53 and MIL-88 were obtained, which contain highly flexible frameworks. ${ }^{13,14,15}$ Recently, studies have been conducted focusing on the chemical functionality of the pores. Functionality can be introduced by synthesizing structures with open coordination sites or by using functionalized organic linker molecules, such

${ }^{a}$ Institut für Anorganische Chemie, Christian-Albrechts-Universität, MaxEyth-Straße 2, D-24118 Kiel, Germany.E-mail: stock@ac.uni-kiel.de; Fax: (+49) 0431-880-1775

${ }^{b}$ Otto-Diels-Institut für Organische Chemie, Christian-AlbrechtsUniversität, Otto-Hahn-Platz 4, D-24098 Kiel, Germany.

$\dagger$ Electronic supplementary information (ESI) available: procedure for the synthesis of 3-azo-phenyl-4,4'-bipyridine, results of the UV/vis and Raman spectroscopic measurements, $\mathrm{CO}_{2}$ and $\mathrm{Ar}$ sorption isotherms, XRD patterns. CCDC reference number 801833. For ESI and crystallographic data in CIF or other electronic format see DOI: $10.1039 / \mathrm{c} 0 \mathrm{dt} 01629 \mathrm{~b}$

\$ Crystal data for CAU-5 (STOE IPDS, Mo-K $\alpha$ radiation, $170 \mathrm{~K}$ ): $\mathrm{H}_{24} \mathrm{C}_{40} \mathrm{~N}_{4} \mathrm{O}_{8} \mathrm{Zn}_{2}, M=819.46 \mathrm{~g} \mathrm{~mol}^{-1}$, monoclinic, space group $C 2 / c, a=$ 19.060(4) $\AA, b=17.898(4) \AA, c=13.932(3) \AA, V=4417.1(15) \AA^{3}, Z=8$, 15528 reflections measured, 4258 independent reflections $\left(R_{\text {int }}=0.0422\right)$, The final $R_{1}$ and $\mathrm{w} R(F 2)$ values $(I>2 \sigma(I))$ are 0.0418 and 0.1202 . The final $R_{1}$ and w $R(F 2)$ values (all data) are 0.0545 and 0.1288 . The goodness of fit on $F^{2}$ was 0.967 . CCDC number 801833 contains the crystallographic data. as aminoterephthalic acid or other terephthalic acid derivatives. ${ }^{5}$ The latter route permits further modification by simple organic reactions. This is known as the post-synthetic modification of MOFs. ${ }^{16,17,18}$

Linker molecules containing an azo-functionality have also been incorporated into the backbone of MOF structures. ${ }^{19,20,21,22,23}$ However, photochemically induced switching has not been achieved so far, since trans-cis-isomerization is hindered in the rigid framework (Fig. 1A). In cases where the azo-group is covalently attached to the inner pore wall, however, switching should be possible (Fig. 1B).

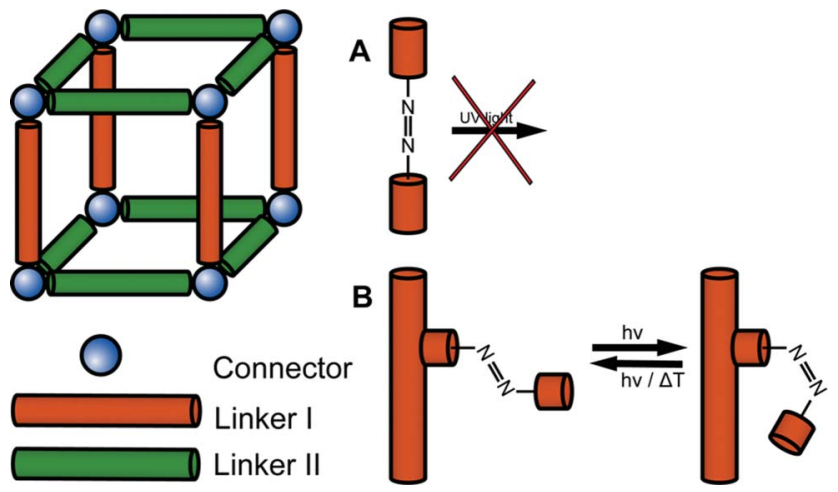

Fig. 1 Two ways to introduce azo-functionalized molecules into MOFs. (A) Azo-linker molecules as part of the backbone of the MOF, (B) azo-group covalently attached to the inner pore wall and protruding into the pore.

The most prominent member of the switchable azo dyes is azobenzene. ${ }^{24,25,26}$ In general the trans-isomer of azobenzene is the thermodynamically more stable form, which exhibits two distinct absorption maxima; one with a lower intensity at $\lambda_{\max }=444 \mathrm{~nm}$ $\left(\mathrm{n} \rightarrow \pi^{*}\right.$ transition) and another maximum at $\lambda_{\max }=316 \mathrm{~nm}(\pi \rightarrow$ $\pi^{*}$ transition). The cis-isomer exhibits an absorption maximum at $\lambda_{\max }=437 \mathrm{~nm}\left(\mathrm{n} \rightarrow \pi^{*}\right.$ transition) and the $\pi \rightarrow \pi^{*}$ transition is shifted to $\lambda_{\max }=270 \mathrm{~nm}$. The trans-isomer can be switched to the $c i s$-isomer by irradiation with UV light $(\lambda \sim 365 \mathrm{~nm})$. This is clearly visible in the $\mathrm{UV} / \mathrm{vis}$ spectra, since the intensity of the band 


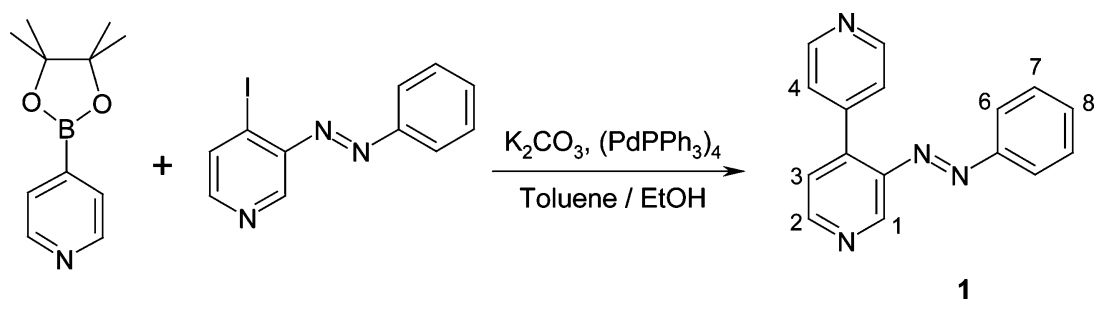

Fig. 2 Final step of the synthesis of 3-azo-phenyl-4,4'-bipyridine (1).

at $\lambda_{\max }=316 \mathrm{~nm}$ decreases and the intensity of the band at $\lambda_{\max }=$ $444 \mathrm{~nm}$ increases. Therefore, both isomers have distinct $\mathrm{UV} / \mathrm{vis}$ spectra and can easily be distinguished. The reversible backswitching can be achieved thermally by heating or by irradiation $(\lambda \sim 440 \mathrm{~nm})$ (Fig. 1).

Since many MOFs are based on mixtures of dicarboxylic acid and diamine linker molecules, ${ }^{27,30}$ we used azo-functionalized $4,4^{\prime}$-bipyridine in combination with a rigid dicarboxylic acid to synthesize new MOFs. Depending on the size of the dicarboxylic acid it should be possible to fine tune the pore size of the MOF in order to allow the incorporation of the azo-functionalized $4,4^{\prime}$ bipyridine linker molecule. ${ }^{30}$

Here we present the synthesis of the switchable azo-linker molecule 3-azo-phenyl-4,4'-bipyridine (1), its use in the synthesis of the new porous MOF $\left[\mathrm{Zn}_{2}(\mathrm{NDC})_{2}(\mathbf{1})\right]$ named CAU-5 $(\mathrm{CAU}=$ Christian-Albrechts-University) and the switching properties of both.

\section{Experimental}

\section{Materials}

The chemicals 3-aminopyridine (Sigma Aldrich), pyvaloyl chloride (Merck), tetramethylethylenediamine (TMEDA, Merck), nitrosobenzene (Fluka), $n$-BuLi, 1.6 M (Acros) and $\mathrm{Pd}\left(\mathrm{PPh}_{3}\right)_{4}$ (ABCR) were obtained commercially and used as received. 3-Azo-phenyl-4,4'-bipyridine (1) was synthesized from 3aminopyridine and pivalic acid chloride in a five step synthesis (Fig. S1 and $\mathrm{S} 2 \dagger$ ). The chemicals $\mathrm{Zn}\left(\mathrm{NO}_{3}\right)_{2} \cdot 6 \mathrm{H}_{2} \mathrm{O}$, methanol and dimethylformamide were purchased from Merck and $\mathrm{BASF}$, respectively, in reagent grade. $\mathrm{Zn}\left(\mathrm{NO}_{3}\right)_{2} \cdot 6 \mathrm{H}_{2} \mathrm{O}$ and methanol were used as obtained. Dimethylformamide was dried over $\mathrm{CaH}_{2}$ and subsequently distilled in vacuo. 2,6Naphthalenedicarboxylic acid was synthesized by hydrolysis of dimethyl-2,6-naphthalenedicarboxylate (Sigma Aldrich).

\section{Syntheses}

The detailed procedure of the five step synthesis of $\mathbf{1}$ is given in the ESI. $\uparrow$ Only the last reaction step leading to $\mathbf{1}$ is presented here in detail (Fig. 2).

3-Azo-phenyl-4,4'-bipyridine (1). A solution of 4-iodo-3(phenylazo)pyridine $(1.23 \mathrm{~g}, 3.9 \mathrm{mmol})$ in $35 \mathrm{ml}$ toluene and $12 \mathrm{ml} \mathrm{EtOH}$ was mixed with 2-(4-pyridyl)-4,4,5,5-tetramethyl1,3,2-dioxaborolane (0.897 g, $4.3 \mathrm{mmol}) . \mathrm{K}_{2} \mathrm{CO}_{3}$ (1.99 g, 12.87 mmol) and tetrakis-(triphenylphosphine)-palladium(0) $(0.075 \mathrm{~g}$, $0.065 \mathrm{mmol}$ ) were added under $\mathrm{N}_{2}$-atmosphere and stirred under reflux for $78 \mathrm{~h}$. The reaction progress was checked by thin layer chromatography. The reaction mixture was cooled to room temperature and $150 \mathrm{~mL}$ ethyl acetate was added. The organic phase was separated and washed twice with $50 \mathrm{~mL}$ water and dried using magnesium sulfate. The solvent was removed under vacuo and the product was chromatographically separated with ethyl acetate over silica gel. ${ }^{1} \mathbf{H}-\mathbf{N M R}\left(220 \mathrm{MHz}, \mathrm{CDCl}_{3}, 300 \mathrm{~K}\right.$, TMS, numbering according to Fig. 2): $\delta=8.93\left(\mathrm{~d},{ }^{4} J=0.54 \mathrm{~Hz}\right.$, $1 \mathrm{H}, \mathrm{H}-1), 8.77$ (d, $\left.{ }^{3} J=5.07 \mathrm{~Hz}, 1 \mathrm{H}, \mathrm{H}-2\right), 8.72\left(\mathrm{dd},{ }^{3} J=4.54 \mathrm{~Hz}\right.$, $\left.{ }^{4} J=1.63 \mathrm{~Hz}, 2 \mathrm{H}, \mathrm{H}-5\right), 7.78\left(\mathrm{dd},{ }^{3} J=6.79 \mathrm{~Hz},{ }^{4} J=3.03 \mathrm{~Hz}, 2 \mathrm{H}\right.$, $\mathrm{H}-4), 7.65$ (dd, $\left.{ }^{3} J=8.28 \mathrm{~Hz},{ }^{4} J=1.39 \mathrm{~Hz}, 1 \mathrm{H}, \mathrm{H}-3\right), 7.50-7.48$ (m, $5 \mathrm{H}, \mathrm{H}-6,7,8)$ ppm. MS (EI, 70 eV): $m / z(\%)=260(100)[\mathrm{M}]^{+}$. MS (CI, isobutane): $m / z(\%)=261(100)[\mathrm{M}+\mathrm{H}]^{+}$.

$\left.\mathbf{Z n}_{\mathbf{2}}(\mathbf{N D C})_{\mathbf{2}} \mathbf{( 1 )}\right]$ (CAU-5). CAU-5 was formed in a solvothermal reaction in $0.2-0.5 \mathrm{ml}$ glass vials (Biotage). The starting materials $\mathrm{Zn}\left(\mathrm{NO}_{3}\right)_{2} \cdot 6 \mathrm{H}_{2} \mathrm{O}(11.3 \mathrm{mg}, 0.037 \mathrm{mmol}), \mathrm{H}_{2} \mathrm{NDC}(8.1 \mathrm{mg}$, $0.037 \mathrm{mmol})$ and $1(4.8 \mathrm{mg}, 0.019 \mathrm{mmol})$ were stirred in a mixture of $0.375 \mathrm{ml} \mathrm{DMF}$ and $0.375 \mathrm{ml} \mathrm{CH}_{3} \mathrm{OH}$ for one day at room temperature. The reaction mixture was heated at $120{ }^{\circ} \mathrm{C}$ in an isothermal oven for two days. The crystalline orange product was filtered and washed three times with $1 \mathrm{ml} \mathrm{DMF}$. The product was dried at room temperature in air followed by activation in an isothermal oven at $80{ }^{\circ} \mathrm{C}$. Elemental analysis of the activated sample $\left[\mathrm{Zn}_{2}(\mathrm{NDC})_{2}(\mathbf{1})\right]\left(M=819 \mathrm{~g} \mathrm{~mol}^{-1}\right)$ calc. (\%): C 58.63, H 2.95, N 6.84; found (\%): 59.45, H 2.65, N 6.7. TG/DTA analysis of CAU-5: no weight loss was detected up to $390{ }^{\circ} \mathrm{C}$ (Fig. S2 $\dagger$ ). Between 390 and $510{ }^{\circ} \mathrm{C}$ a total weight loss of $80.6 \%$ (weight loss calc. $80.1 \%$ ) was observed in two steps which are due to the oxidative decomposition. The final product was identified as $\mathrm{ZnO}$ by X-ray powder diffraction (XRPD).

\section{Characterization}

Elemental analyses were carried out using a Eurovektor EuroEA Elemental Analyzer. Raman spectra were recorded using a Bruker FRA 106 Raman spectrometer. UV-measurements were performed with a Cary 5000 (Varian). Switching experiments of $\mathbf{1}$ in solution and $\mathrm{CAU}-5 / \mathrm{BaSO}_{4}$ mixtures were performed using a $150 \mathrm{~W}$ Xenon-lamp and an Orieal Apex monochromator (Newport Corporation). Thermogravimetric (TG) analyses were carried out in air $\left(25 \mathrm{ml} \mathrm{min}{ }^{-1}, 25-900{ }^{\circ} \mathrm{C}, 4{ }^{\circ} \mathrm{C} \mathrm{min}-1\right)$ on a NETZSCH-STA-449 C thermal analyzer. Sorption measurements were realized with a BELSORP Max from Bel Japan. INC; for proper activation the sample was heated in vacuum for $5 \mathrm{~h}$ at $150{ }^{\circ} \mathrm{C}$. XRPD measurements were carried out in transmission mode using a STOE high-throughput powder diffractometer equipped with an image-plate position-sensitive detector (IPPSD).

Switching experiments of pure microcrystaline powder of CAU5 were performed using two LED light sources from NICHIA $(\lambda=365 \mathrm{~nm}:$ NC4U133E and $\lambda=455 \mathrm{~nm}$ : NS6C083A). The 
Table 1 Crystal data for CAU-5 $\left[\mathrm{Zn}_{2}(\mathrm{NDC})_{2}(\mathbf{1})\right], 1$ = 3-azo-phenyl-4,4'bipyridine

\begin{tabular}{ll}
\hline Chemical formula & $\mathrm{Zn}_{2}(\mathrm{NDC})_{2}(\mathbf{1})$ \\
\hline Crystal system & Monoclinic \\
Space group & $C 2 / c$ \\
$a / \AA$ & $19.060(4)$ \\
$b / \AA$ & $17.898(4)$ \\
$c / \AA$ & $13.932(3)$ \\
$\beta /^{\circ}$ & $111.66(1)$ \\
$V / \AA^{3}$ & $4417.1(15)$ \\
$Z$ & 8 \\
Formula weight/g mol ${ }^{-1}$ & 819.46 \\
Total number of data collected & 15528 \\
Unique/obsd data/I $>2 \sigma(I)$ & $4258 / 3350$ \\
$R($ int $)$ & 0.0422 \\
$R_{1} / I>2 \sigma(I)$ & 0.0418 \\
$R_{1}$, w $R_{2}($ all data $)$ & $0.0545,0.1288$ \\
\hline
\end{tabular}

samples were analysed using a PANalytical X'Pert diffractometer equipped with a PixCell semiconductor detector system using $\mathrm{Cu}$ $\mathrm{K} \alpha$ irradiation. All measurements were performed in reflection geometry.

\section{Structure determination and refinement}

CAU-5 [ $\left.\mathrm{Zn}_{2}(\mathrm{NDC})_{2}(\mathbf{1})\right]$ crystallizes to form air-stable orange rods $\left(0.07 \times 0.07 \times 0.12 \mathrm{~mm}^{3}\right)$. The single-crystal XRD measurement was performed on a STOE IPDS diffractometer. The instrument is equipped with a fine focus sealed tube (Mo-K $\alpha$ radiation, $\lambda=71.073 \mathrm{pm}$ ). For data reduction and absorption correction the programs XRED and XSHAPE were used. ${ }^{28}$ The crystal structure was solved by direct methods and refined using the program package SHELXTL. ${ }^{29}$ Since for the single-crystal XRD measurement a non activated crystal was used, disordered guest molecules were present in the pores. Therefore, for the final structure refinement the SQUEEZE procedure was applied as implemented in the PLATON software. ${ }^{31}$ Results of the structure determination are summarized in Table 1.

\section{Switching experiment}

The switching experiments of 3-azo-phenyl-4,4'-bipyridine (1) were performed in ethanol using a quartz cuvette. Successful switching was demonstrated by recording the UV/vis spectra. The stirred solution was irradiated with UV light $(\lambda=365 \mathrm{~nm})$ for $1 \mathrm{~h}$ to switch the trans-isomer into the $c i s$-isomer. The reversible backswitching was achieved by irradiation with visible light $(\lambda=440$ $\mathrm{nm}$ ) for $1 \mathrm{~h}$. This switching experiment was repeated twice.

The switching experiments and $\mathrm{UV} / \mathrm{vis}$ measurements for CAU5 were performed in a mixture of the microcrystalline powder and $\mathrm{BaSO}_{4}$. The UV/vis spectra were measured in reflection geometry. The data was transformed into adsorption spectra using the Kubelka Munk equation. After 15 min irradiation time the photostationary state was reached (Fig. S3†). The back-switching from the cis- to trans-isomer could also be achieved thermally at room temperature or by irradiation with visible light $(\lambda=440 \mathrm{~nm})$.

The switching was also investigated with XRPD measurements using a ground sample of CAU-5. After recording a XRPD pattern, the sample was irradiated with UV light $(\lambda=365 \mathrm{~nm})$ using a LED light source. After an irradiation time of $15 \mathrm{~min}$ a second XRPD pattern was recorded. The back switching was achieved with visible light $(\lambda=455 \mathrm{~nm})$ and a XRPD pattern was also recorded. This experiment was performed three times.

\section{Results and discussion}

3-Azo-phenyl-4,4'-bipyridine (1) was obtained as a pure phase product and employed in the synthesis of CAU-5. Starting from the synthesis procedure of $\left[\mathrm{Zn}_{2}(\mathrm{NDC})_{2}\left(4,4^{\prime}\right.\right.$-bipy $\left.)\right]$, reported by $\mathrm{Kim}$ et al., ${ }^{30}$ the partial and full replacement of $4,4^{\prime}$-azobipyridine by 1 was investigated. While partial replacement led only to the same threefold interpenetrated, non porous structure, full replacement of 4,4'-bipyridine by $\mathbf{1}$ gave rise to the porous title compound CAU-5 (Fig. S4 $\dagger$ ). The framework structure of CAU-5 crystallizes in the monoclinic space group $C 2 / c$ with one $\mathrm{Zn}$-atom, one $\mathrm{NDC}^{2-}$ ion and one-half azobipyridine-molecule in the asymmetric unit. $\mathrm{Zn}$-containing paddle wheel units are observed which are bridged by naphthalenedicarboxylate ions in the $a, b$-plane to form a $2 \mathrm{D}$ square-grid (Fig. 3). The axial sites of these paddle wheel units are occupied by the azobipyridine linker molecules $\mathbf{1}$, and the azo-phenyl groups are disordered. In contrast to $\left[\mathrm{Zn}_{2}(\mathrm{NDC})_{2}\left(4,4^{\prime}-\right.\right.$ bipy)] which has a threefold interpenetrated structure, in CAU-5 only twofold interpenetration is observed. This is due to the steric demand of $\mathbf{1}$. The purity of CAU-5 was demonstrated by XRPD measurements, TG/DTA (Fig. S2 $\dagger$ ) and elemental analysis as well as Raman spectroscopy. The calculated and measured XRPD patterns compare well and only one additional reflection of low intensity was observed at $15^{\circ}$ ( 2 theta), which is due to the presence of guest molecules in the pores (Fig. 4).

The incorporation of the linker molecule 1 was also confirmed by Raman spectroscopy (Fig. S5, Table S1 $\uparrow$ ). The characteristic band for the symmetric $\mathrm{N}=\mathrm{N}$ vibration of the trans-isomer is located at $1443 \mathrm{~cm}^{-1}$ and $1444 \mathrm{~cm}^{-1}$ in the spectra of the pure linker molecule 1 and CAU-5, respectively. The Raman spectrum of CAU-5 contains the characteristic bands of both linker molecules, the naphthalenedicarboxylic acid as well as $\mathbf{1}$.

The permanent porosity of CAU-5 was demonstrated by $\mathrm{N}_{2}$, $\mathrm{CO}_{2}$ and Ar sorption measurements (Fig. 5, Fig. S6 and S7, $\dagger$ respectively). The $\mathrm{N}_{2}$ sorption curve of the activated sample $\left(150{ }^{\circ} \mathrm{C}, 5 \mathrm{~h}\right.$ in vacuum) shows a sharp increase at low $p / p_{0}$ values and a well defined plateau, which is typical for a type I isotherm. Fitting the data with the Brunauer-Emmett-Teller (BET) equation, a specific surface area of $554 \mathrm{~m}^{2} \mathrm{~g}^{-1}$ is calculated. Using the $t$-plot method, a micropore volume of $0.23 \mathrm{~cm}^{3} \mathrm{~g}^{-1}$ is obtained. This value compares well with the pore volume $\left(0.225 \mathrm{~cm}^{3} \mathrm{~g}^{-1}\right)$ calculated using PLATON. ${ }^{31}$

The results of the switching experiments of 3-azo-phenyl-4,4'bipyridine (1) in solution are shown in Fig. 6 . The maximum at $\lambda=$ $321 \mathrm{~nm}$ can be assigned to the $\pi \rightarrow \pi^{*}$ transition of the azo-group, the band with a maximum at $\lambda=460 \mathrm{~nm}$ to the $\mathrm{n} \rightarrow \pi^{*}$ transition. Both maxima are well separated and can be easily distinguished. In the trans-isomer, the $\pi \rightarrow \pi^{*}$ transition has a higher intensity than the $\mathrm{n} \rightarrow \pi^{*}$ transition. Irradiation for $1 \mathrm{~h}$ with UV light $(\lambda=$ $365 \mathrm{~nm}$ ) leads to an increase of the band at $\lambda=460 \mathrm{~nm}$ as well as a decrease of the band at $\lambda=321 \mathrm{~nm}$ (Fig. 6: blue, gray, and green line). This is due to the trans-cis-isomerization. The reversible back switching was achieved using visible light $(\lambda=440 \mathrm{~nm})$ as shown in Fig. 6 (yellow, red, and purple line). The switching experiment was repeated twice to demonstrate the reversible switching behaviour of 3-azo-phenyl-4,4'-bipyridine in ethanol. 

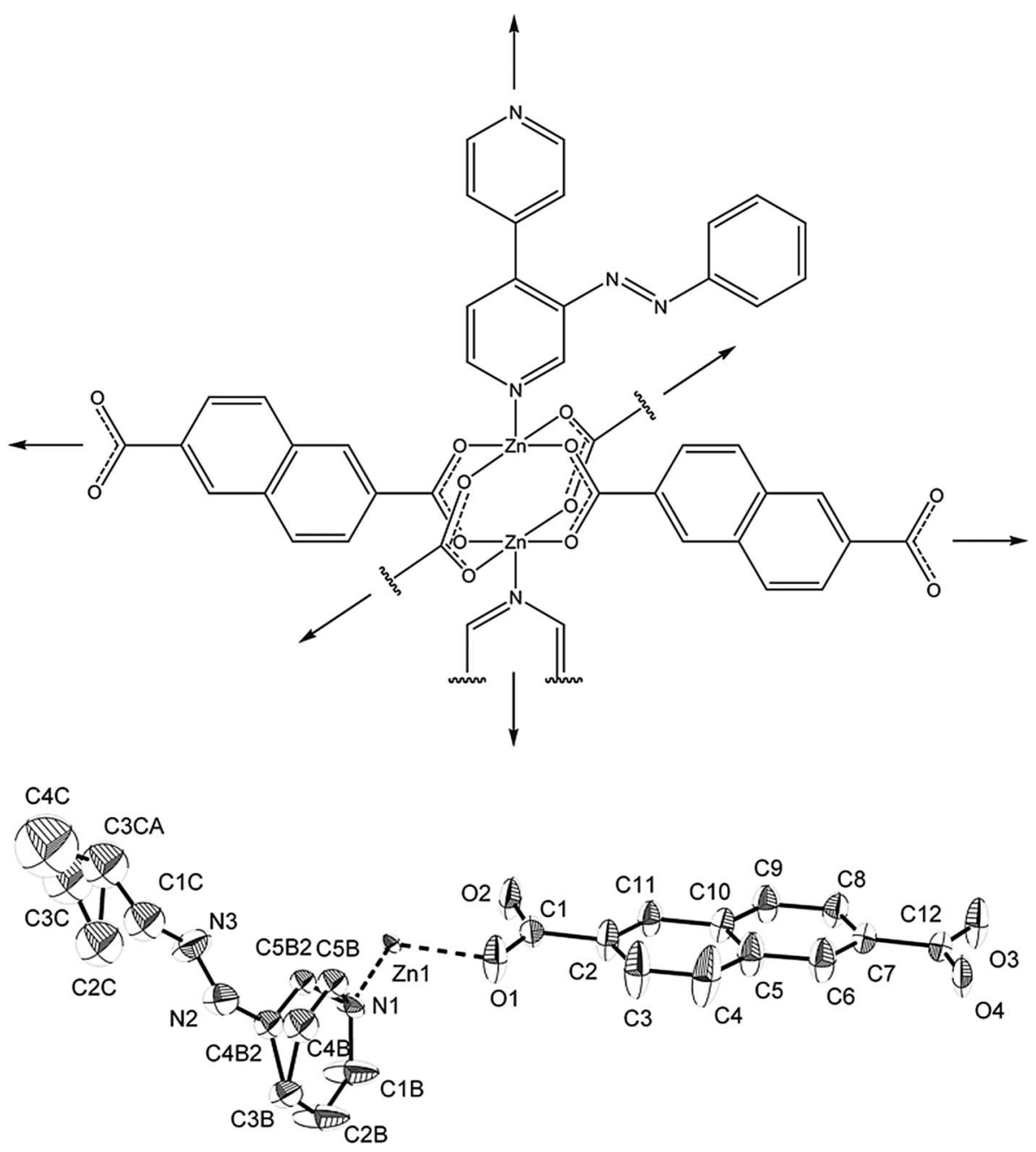

Fig. 3 Top: paddle wheel unit containing the 3-azo-phenyl-4,4'-bipyridine and the naphthalenedicarboxylate ions as observed in the crystal structure of CAU-5; bottom: ORTEP presentation of the asymmetric unit, C1B, C2B, C3B, C4B, C4B2, C5B and C5B2 constitute the 4,4'-bipyridine molecule, N2, $\mathrm{N} 3, \mathrm{C} 1 \mathrm{C}, \mathrm{C} 2 \mathrm{C}, \mathrm{C} 3 \mathrm{C}, \mathrm{C} 3 \mathrm{CA}$ and $\mathrm{C} 4 \mathrm{C}$ the azo-phenyl moiety. Hydrogen atoms are omitted for clarity; thermal ellipsoids are shown at $85 \%$ probability.

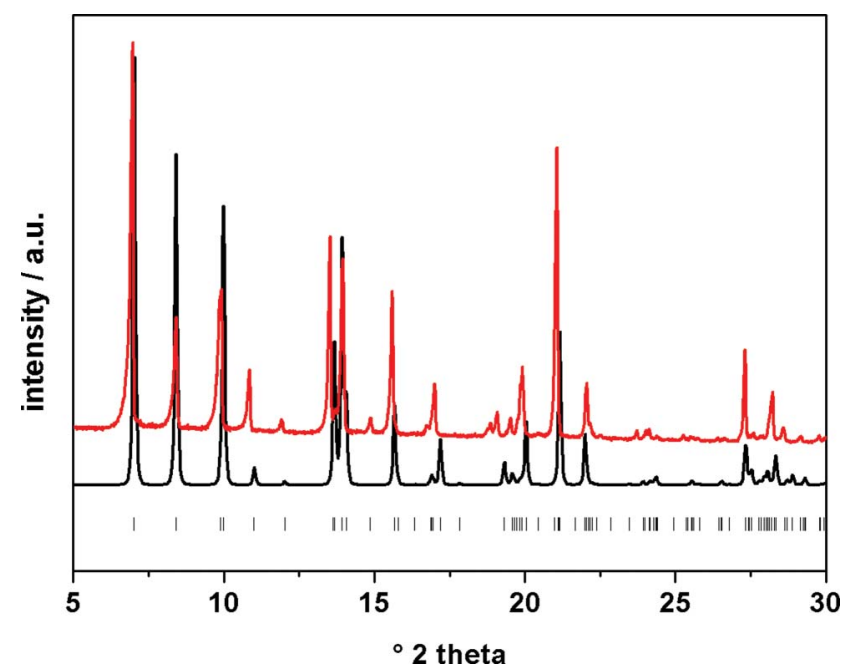

Fig. 4 Calculated (bottom) and measured (top) XRPD patterns of CAU-5. Allowed reflection positions are marked by ticks.

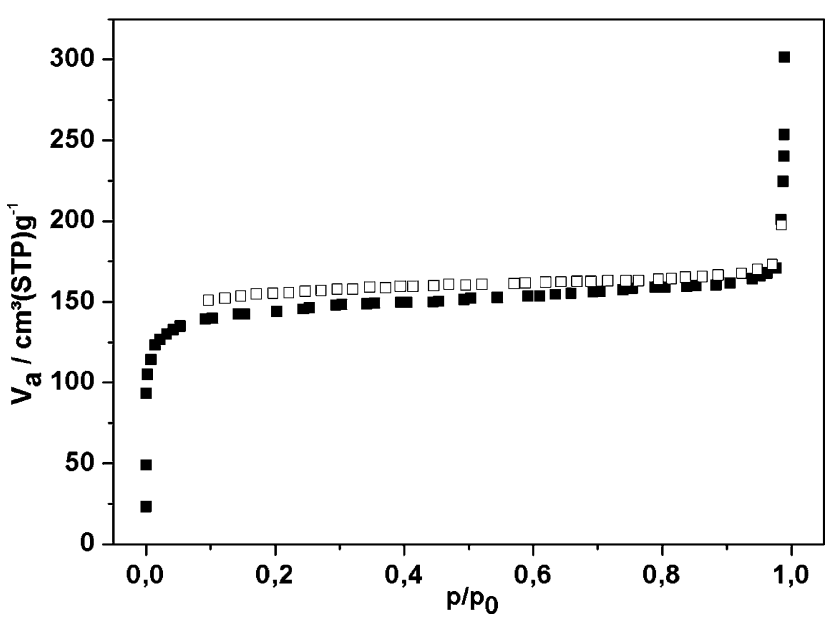

Fig. $5 \mathrm{~N}_{2}$ adsorption- (filled squares) and desorption- (open squares) isotherm of CAU-5. 

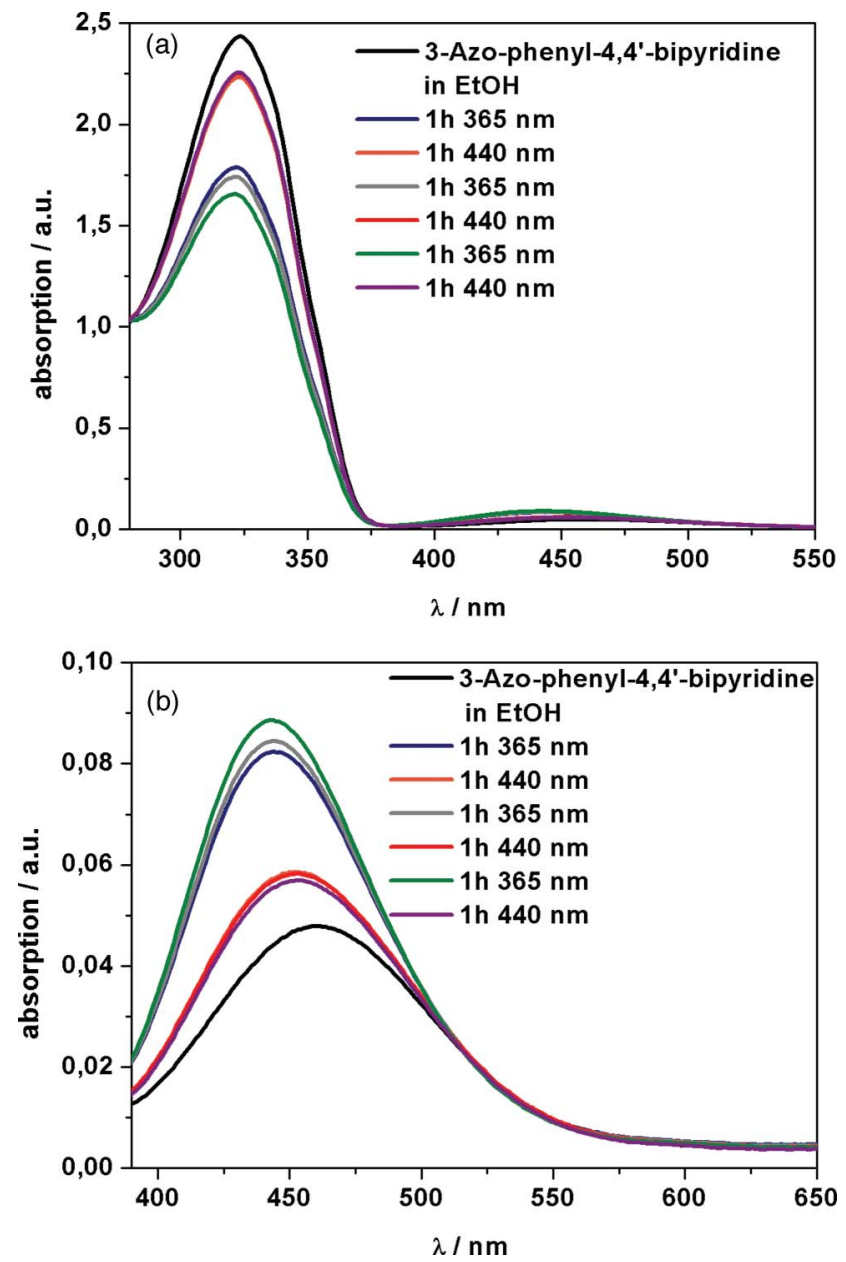

Fig. 6 Results of the UV/vis switching experiments of 3-azo-phenyl-4,4'-bipyridine in ethanol. Top: UV/vis spectra recorded from $250-550 \mathrm{~nm}$; bottom: detailed view from $390-650 \mathrm{~nm}$.

The analogous UV/vis switching experiment was performed using well ground CAU-5 in a $\mathrm{BaSO}_{4}$ matrix (Fig. 7). Upon irradiation with UV light $(\lambda=365 \mathrm{~nm})$ the intensity of the band at $\lambda=462 \mathrm{~nm}$ increased and the band at $\lambda=365 \mathrm{~nm}$ decreased

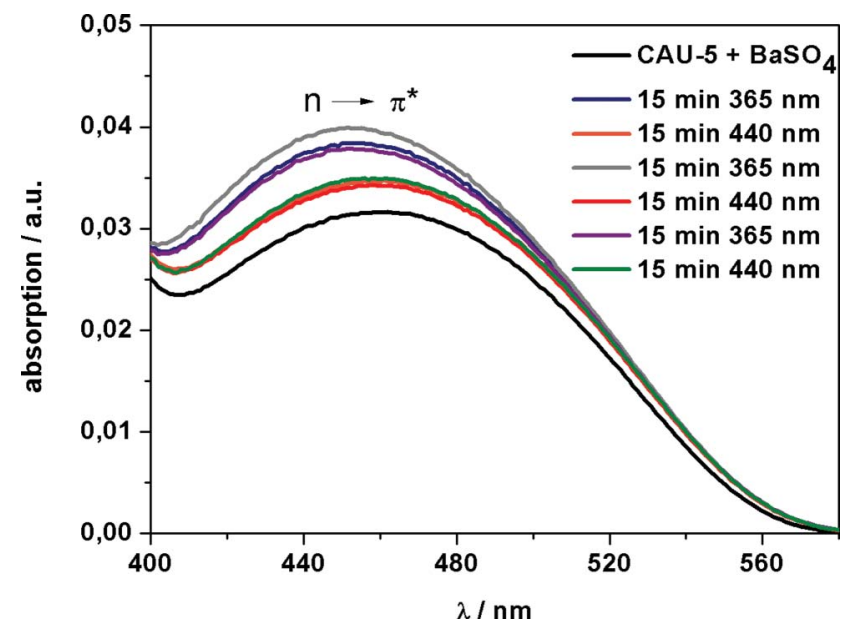

Fig. 7 Results of the UV/vis switching experiment of microcrystalline CAU-5 in a $\mathrm{BaSO}_{4}$ matrix.
(Fig. 7, Fig. S8 $\dagger$ ). The back switching was achieved employing visible light $(\lambda=440 \mathrm{~nm})$. The intensity of the band at $\lambda=462 \mathrm{~nm}$ decreased again, due to higher trans-isomer concentration. The results of repeated switching are shown in Fig. S9. $\dagger$

Switching from the cis- to trans-isomer could also be achieved thermally (Fig. S10†). After switching from the trans- to the cisisomer, the sample was left at room temperature in the dark for $24 \mathrm{~h}$. The cis-isomer partially switched back to the trans-isomer.

To prove that the switching takes place in the crystalline network, switching experiments using pure microcrystalline powder of CAU-5 were performed. Trans-cis-isomerization should lead to changes in the reflection intensities of XRPD patterns. As expected, irradiation of the CAU- 5 crystals with UV light ( $\lambda=$ $365 \mathrm{~nm}$ ) led to small changes in the reflection intensities in the XRPD pattern (Fig. 8a). While no obvious shifts of the reflections positions are detected, two small broad reflections at 10.1 and $15.3^{\circ}$ ( 2 theta) are observed. After the irradiation with visible light $(\lambda=455 \mathrm{~nm})$ the XRPD patterns showed nearly the same intensities as before and the additional reflections were no longer present (Fig. 8b). The experiment was performed three times and showed the same results. Although a detailed crystallographic explanation is not possible at this stage, the results demonstrate unequivocally that the trans-cis-isomerization leads to changes in the crystal structure and therefore to changes in the XRPD patterns.

To the best of our knowledge, CAU- 5 is the first MOF with a reversible switching azo-functionality inside the pores. In the past, different metal-organic frameworks with azo-functionalized linker molecules were described. For example MOF-9, which consists of $\mathrm{Tb}_{2} \mathrm{C}_{6} \mathrm{O}_{12}$ clusters connected by azobenzenedicarboxylic acid molecules. ${ }^{20}$ Another example was recently reported by Kuchár et al., who synthesized a compound based on Zn(II) atoms, terephthalic acid and 4,4'-azo(bis)pyridine molecules. ${ }^{22}$ In both compounds, the azo-group is part of the rigid backbone of the $\mathrm{MOF}$ and therefore switching is strongly hindered.

Although we were able to show the first example of a switchable azo-functionality inside a metal-organic framework, the switching effect has to be improved. This could possibly be achieved by preventing the interpenetration of the network. Interpenetration can be prevented by using sterically demanding organic linker molecules. This was previously demonstrated for the compound $\mathrm{Zn}_{2} \mathrm{BDC}_{2}\left(4,4^{\prime}\right.$-bipy) which has a twofold interpenetrated structure. ${ }^{30}$ Replacing terephthalic acid by tetramethylterephthalic acid, a non-interpenetrating, porous compound is obtained. ${ }^{30}$ Present results show a similar trend. The combination of naphthalenedicarboxylic acid and 4,4'-bipyridine leads to a threefold interpenetrated structure. By replacing 4,4'-bipyridine by the sterically more demanding linker molecule $\mathbf{1}$, a twofold interpenetrated network structure is obtained, which shows permanent porosity. Therefore, to improve the switching properties in our system, one could imagine further increasing the steric demand of the linker molecules and thus avoid interpenetration.

\section{Conclusions}

The porous, air stable metal-organic framework compound, $\left[\mathrm{Zn}_{2}(\mathrm{NDC})_{2}(\mathbf{1})\right](\mathrm{CAU}-5)$ with a free, switchable azo-group inside the pores was obtained by solvothermal synthesis. Elemental and thermal analysis confirmed purity. Although the CAU-5 structure 

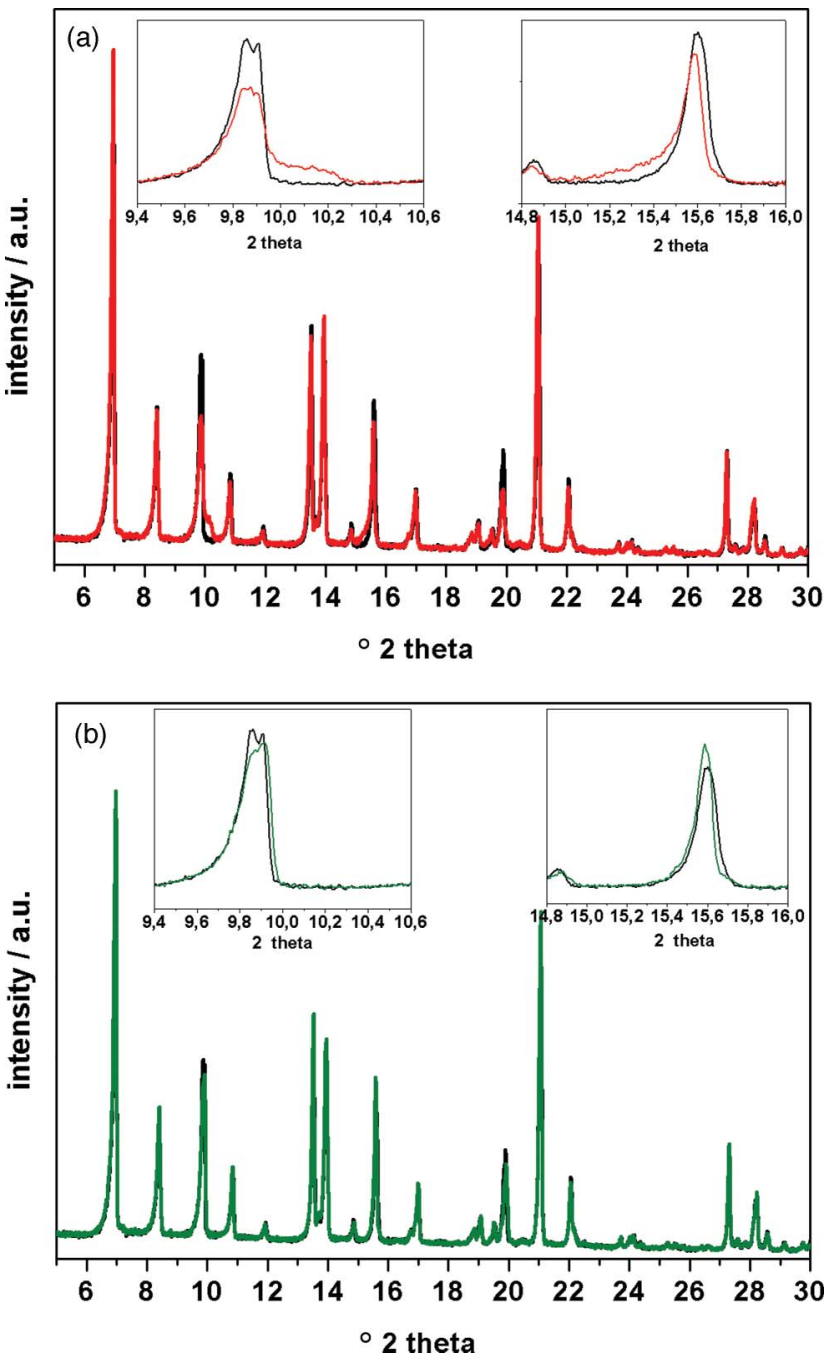

Fig. 8 (a) Powder pattern of CAU-5 before (black) and after irradiation with UV light $(\lambda=365 \mathrm{~nm})$ (red line). The reflection intensities change and two new broad reflections occur at 10.1 and $15.3^{\circ}$ (2 theta). (b) Powder pattern of CAU-5 before (black) and after irradiation with visible light $(\lambda=455 \mathrm{~nm})$ (green line). The recorded powder pattern of CAU-5 showed nearly the same intensities as before and the additional reflections are no longer present.

contains two interpenetrating networks, it exhibits microporosity that was demonstrated by sorption measurements. UV/vis experiments unequivocally showed the possibility of repeated reversible switching.

\section{Acknowledgements}

This work has been supported by the State of Schleswig-Holstein and the Deutsche Forschungsgemeinschaft (DFG) via the SFB 677 Function by Switching. The authors thank Uschi Cornelissen and Stephanie Pehlke for supporting all spectroscopic measurements, Inke Jess and Christian Näther for single crystal measurements,
Adam Wutkowski for TG/DTA measurements, Christina Rutz for support in the preparation of 3-azo-phenyl-4,4'-bipyridine and Mark Feyand for additional help solving the single crystal structure.

\section{Notes and references}

1 R. E. Morris and P. S. Wheatly, Angew. Chem., Int. Ed., 2008, 47, 4966.

2 R. Babarao and J. Jiang, Langmuir, 2008, 24, 6270.

3 A. U. Czaja, N. Trukhan and U. Mueller, Chem. Soc. Rev., 2009, 38, 1284.

4 U. Mueller, M. Schubert, F. Teich, H. Puetter, K. Schierle-Arndt and J. Pastré, J. Mater. Chem., 2006, 16, 626.

5 C. Serre, F. Millange, C. Thouvenot, M. Noguès, G. Marsolier, D. Louër and G. Férey, J. Am. Chem. Soc., 2002, 124, 13526.

6 H. K. Chae, D. Y. Siberio-Pérez, J. Kim, Y.-B. Go, M. Eddaoudi, A. J. Matzger, M. O'Keeffe and O. M. Yaghi, Nature, 2004, 427, 523.

7 K. Koh, A. G. W.-F. and A. J. Matzger, Angew. Chem., Int. Ed., 2008, 47, 677.

8 X.-S. Wang, S. Ma, D. Sun, S. Parkin and H.-C. Zhou, J. Am. Chem. Soc., 2006, 128, 16474.

9 A. Sonnauer, F. Hoffmann, M. Fröba, L. Kienle, V. Duppel, M. Thommes, C. Serre, G. Férey and N. Stock, Angew. Chem., Int. Ed., 2009, 48, 3791.

10 H. Deng, C. J. Doonan, H. Furukawa, R. B. Ferreira, J. Towne, C. B. Knobler, B. Wang and O. M. Yaghi, Science, 2010, 327, 846.

11 M. Eddaoudi, J. Kim, N. Rosi, D. Vodak, J. Wachter, M. O'Keeffe and O. M. Yaghi, Science, 2002, 295, 469.

12 S. Kitagawa, R. Kitaura and S. Noro, Angew. Chem., Int. Ed., 2004, 43, 2334.

13 C. Mellot-Draznieks, C. Serre, S. Surblé, N. Audebrand and G. Férey, J. Am. Chem. Soc., 2005, 127, 16275.

14 C. Serre, C. Mellot-Draznieks, S. Surblé, N. Audebrand, Y. Filinchuk and G. Férey, Science, 2007, 315, 1828.

15 C. Serre, F. Millange, C. Thouvenot, M. Noguès, G. Marsolier, D. Louër and G. Férey, J. Am. Chem. Soc., 2002, 124, 13526.

16 J. S. Costa, P. Gamez, C. A. Black, O. Roubeau, S. J. Teat and J. Reedijk, Eur. J. Inorg. Chem., 2008, (10), 1551.

17 K. K. Tanabe, Z. Wang and S. M. Cohen, J. Am. Chem. Soc., 2008, 130, 8508 .

18 Z. Wang and S. M. Cohen, Chem. Soc. Rev., 2009, 38, 1315.

19 Y. Liu, J. F. Eubank, A. J. Cairns, J. Eckert, V. Ch. Kravtsov, R. Luebke and M. Eddaoudi, Angew. Chem., Int. Ed., 2007, 46, 3278.

20 T. M. Reineke, M. Eddaoudi, D. Moler, M. O'Keeffe and O. M. Yaghi, J. Am. Chem. Soc., 2000, 122, 4843.

21 Z.-F. Chen, R.-G. Xiong, B. F. Abrahams, X.-Z. You and C.-M. Che, J. Chem. Soc., Dalton Trans., 2001, (17), 2453.

22 V. Zeleňák, Z. Vargová, M. Almáši, A. Zeleňáková and J. Kuchár, Microporous Mesoporous Mater., 2010, 129, 354.

23 C.-M. Jin, Z. Zhu, Z.-F. Chen, Y.-J. Hu and X.-G. Meng, Cryst. Growth Des., 2010, 10, 2054.

24 H. Dürr, H. Bouas-Laurent, Photochromism, 1st Edition, Elsevier, Amsterdam, 1990.

25 F. Lenci, W. Horspool, CRC Handbook of Organic Photohemistry and Photobiology, 2nd Edition, CRC Press LLC, Florida, 2004.

26 J. Griffiths, Chem. Soc. Rev., 1972, 1, 481.

27 B. Chen, C. Liang, J. Yang, D. S. Contreras, Y. L. Clancy, E. B. Lobkovsky, O. M. Yaghi and S. Dai, Angew. Chem., Int. Ed., 2006, 45, 1390.

28 XRED Version 1.19, X-SHAPE Version 1.06, Stoe \& Cie GmbH, Darmstadt, Germany, 1999.

29 G. M. Sheldrick, SHELXTL-PLUS Crystallographic System, Siemens, Analytical X-Ray Instruments Inc. Madison, WI, 1992.

30 H. Chun, N. Dybtsev, H. Kim and K. Kim, Chem.-Eur. J., 2005, 11, 3521.

31 A. L. Spek, PLATON, A Multipurpose Crystallographic Tool, Utrecht University, Utrecht, The Netherlands, 2005. 